IJBPAS, August, Special Issue, 2021, 10(8): 381-394

ISSN: 2277-4998

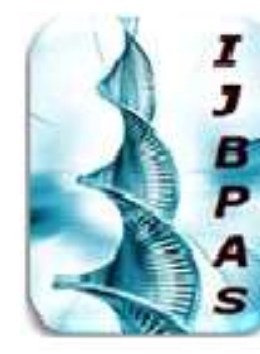

International Journal of Biology, Pharmacy

and Allied Seiences (IJBPAS)

'A Bridge Betuen Caboratory and Qnendo'

WwW.ijbpas.com

\title{
ESTHETICS IN COMPLETE DENTURE
}

\section{SUBASHRI.A ${ }^{1}$ AND DHANRAJ GANAPATHY ${ }^{2 *}$}

1: Saveetha Dental College and Hospitals, Saveetha Institute of Medical and Technical Sciences, Saveetha University, Chennai, India

2: Professor and Head, Department of Prosthodontics, Saveetha Dental College and Hospitals, Saveetha Institute of Medical and Technical Sciences, Saveetha University, Chennai, India

*Corresponding Author: E Mail: Dr. Dhanraj Ganapathy: dhanraj@saveetha.com

Received 19 ${ }^{\text {th }}$ March 2021; Revised 20 ${ }^{\text {th }}$ April. 2021; Accepted $19^{\text {th }}$ May 2021; Available online $1^{\text {st }}$ Aug. 2021

\section{https://doi.org/10.31032/IJBPAS/2021/10.8.1028}

\begin{abstract}
Inseparable and interdependent factors for successful prosthodontics treatment are function and aesthetics. Adequate function and refinement must be done as prosthodontic service. A more natural and harmonious prosthesis can be made when the dysesthetic and dentogenic concept are applied in the dentures. This not only increases patients comfort but also increases functional use. Great aesthetics can be achieved by simple methods. This study was conducted among the patients visiting a private dental college who were completely edentulous. The records were taken from the period of June 2019- March 2020. A total of case sheets were reviewed and the observations were recorded under 6 parameters and given a score ranging from 0-2. Results were then tabulated and imported to SPSS software to obtain correlation between the factors. Out of case sheets reviewed, were males and females. Highly significant association was found between the gender and 5 parameters except the midline. Females had a more aesthetic smile line than the males. Further studies can be done by including more parameters. Aesthetic attention must be given even to complete denture wearers as it can satisfy the patient both functionally and aesthetically.
\end{abstract}

Keywords: Complete denture, Smile line, Midline, Long axis, Gingival exposure 


\section{INTRODUCTION}

In this modern society, good appearance often means a lot in both professional and personal lives. Both men and women are very conscious about their appearance [1]. The cultural definition of dental beauty differs, however, across different populations, regions, countries, and even continents. It is also dynamic, with parameters of dental beauty changing across time, for varying reasons [2]. There is a high demand for cosmetic dentistry because people want to resemble their favourite celebrity. Aesthetics is not only concerned with smile correction but also deals with profile correction and also jaw [3]. Because of increased concern it is important to understand the factors that decide whether a smile is attractive or not. The study of beauty norms and standards is done to come up with the "golden smile" that can be used in diagnostic methods and aesthetic treatment plans [4]. An ideal smile may not be the right term instead a balanced smile can be achieved by proper positioning of teeth [5]. A smile which appears attractive in the first glance need not be so in the second, this explains the concept of threshold level of acceptable deviation [6-8]. Facial attractiveness and smile attractiveness are closely connected to each other because in any social interaction attention of the speaker is directed towards the mouth and eyes of the speaker [9]. An attractive smile does not only depend on tooth position, shape, size or color of the teeth but also on the visible gingiva and frame of the lips. Smile attractiveness plays a major role in the social life of a person. An individual evaluating their own smile in photographs is rare because they are mostly consciously posed. The mouth is the centre of attraction and thus a smile is the most important factor in designing the attractiveness of the face [10].

Aesthetic dentistry can be defined as the art and science of dentistry applied to create or enhance beauty of an individual within functional and physiological limits [11]. Function is the foundation of aesthetics. A basic aesthetic concept for all phases of dentistry is the dentogenic theory of aesthetics [12]. It can be explained by three factors- sex, personality and age commonly known as the SPA concept [13]. The word dysesthetic gives a life to the denture, considered as the second factor for restoration. Greater aesthetics can be achieved by using these factors [14].

An important step in obtaining proper aesthetics is the teeth selection. In complete dentures, the dentist must often not only 
select the teeth with proper form and size but also ideal shade [15]. Many different guides are available for selection of teeth for edentulous patients. To give a proper aesthetic denture one must also deal with geometrical analysis of facial form, arch form, profiles and various parameters like age, sex and personality of patients [16]. Teeth selection is not a simple procedure but requires knowledge and dexterity. Teeth form must be selected before the commencement of teeth selection. A properly made prosthesis without a fusion of aesthetics is always considered bad. The aesthetics must be visualised in relation to patients and then translated [17]. Artistic ability, experience and observations determines the clinical success of dentists [18]. Previously our team had conducted numerous clinical trials[19,20] and lab animal studies, surveys [21, 22], reviews [23], in-vitro studies [24,25], plant studies [26] and various other entities [27-29] over the past 5 years. Therefore this idea of esthetics in complete denture stemmed from the previous studies done.

\section{MATERIALS AND METHOD}

The baseline study population was 347 case records of patients who were completely edentulous and visited Saveetha dental college from the period of June 2019 - April
2020. The study setting was the University setting. This retrospective study was approved by the following ethical approval number of the university, SDC/SIHEC/2020/DIASDATA/0619-0320.

Type III examination procedure was adopted and 347 ase sheets were reviewed. Cross verification of data for error identification was done. Simple random technique followed to minimize sampling bias. Internal validity taken were non probability inclusion of all subjects and External validity were Homogenization, replication and cross comparison.

Data collection was reviewed and analysed from 86,000 patient records between June 2019 to March 2020. Data entered in Microsoft Excel sheet and then imported to SPSS software.Variable definition process was done using table and graphical illustrations. Descriptive statistics tests and Inferential statistics were used. IBM SPSS version 20.0 statistical software used. Dependent variables taken were gender,age, photographs. Independent variables were name and location. The data then transferred to a host computer and processed for further analysis.

Each case sheet was reviewed carefully and summarized using 5 parameters. Each was graded based on 0-2 scores. 0 being 
unacceptable, 1 as acceptable and 2 as good.

The 5 parameters included in the study are:

1. Midline

2. Smile line

3. Long axis of tooth

4. Gingival exposure

\section{RESULTS}

Distribution of subjects based on gender of the population. Male participants are about $58.21 \%$ and female participants about $41.79 \%$ (Figure 1). Distribution of midline shows, $47.8 \%$ of patients had good midline status when compared to others (Figure 2). Distribution of smile line shows, $50.7 \%$ of the patients had a good smile line when compared to others (Figure 3). Distribution of long axis of tooth shows, only $36.3 \%$ of the subjects had good long axis inclinations of teeth where 53.9\% had acceptable (Figure 4). Distribution of gingival exposure shows, only $33.4 \%$ of subjects had good gingival exposure whereas $49 \%$ were acceptable

\section{(Figure 5).}

Female participants who had unacceptable midline are $40.91 \%$ and the male participants about $59.09 \%$, Acceptable midline for female participants are $36.48 \%$ and male participants are $63.52 \%$ (Figure 6). Female participants who have a good midline are about $46.99 \%$ and male participants $53.01 \%$ in terms of midline with no statistical significant difference found. (Pearson Chi-square Test $\mathrm{P}=0.158, \mathrm{P}>0.05$ ). Female participants have an unacceptable smile line of about $34.78 \%$ and the male participants about $65.2 \%$, Acceptable smile line in female participants is about $34.46 \%$ and male participants about $65.54 \%$. Female participants who have a good smile line are about $48.86 \%$ and male participants $65.54 \%$ in terms of smile line with a statistical significant difference found. (Pearson Chi-square Test $\mathrm{P}=0.025, \mathrm{P}<0.05$ )

\section{(Figure 7).}

Female participants who have an unacceptable inclination of teeth are about $41.18 \%$ and the male participants about $58.82 \%$, Acceptable inclinations of female participants are about $34.22 \%$ and male participants are $65.78 \%$. Female participants who have a good long axis of tooth are about $53.17 \%$ and male participants $46.83 \%$ in terms of long axis of tooth with a statistical significant difference found. (Pearson Chi-square Test $\mathrm{P}=0.004, \mathrm{P}<0.05$ ) (Figure 8). Female participants who have an unacceptable gingival exposure are about $39.34 \%$ and the male participants about $60.66 \%$, Acceptable gingival exposure for female participants are about $35.88 \%$ and male participants about $64.12 \%$. Female participants who have a good gingival exposure are about $51.72 \%$ and male participants about $48.28 \%$ in terms of gingival exposure with a statistical significant difference found.(Pearson Chi-square Test $\mathrm{P}=0.026, \mathrm{P}<0.05$ ). (Figure 9). 


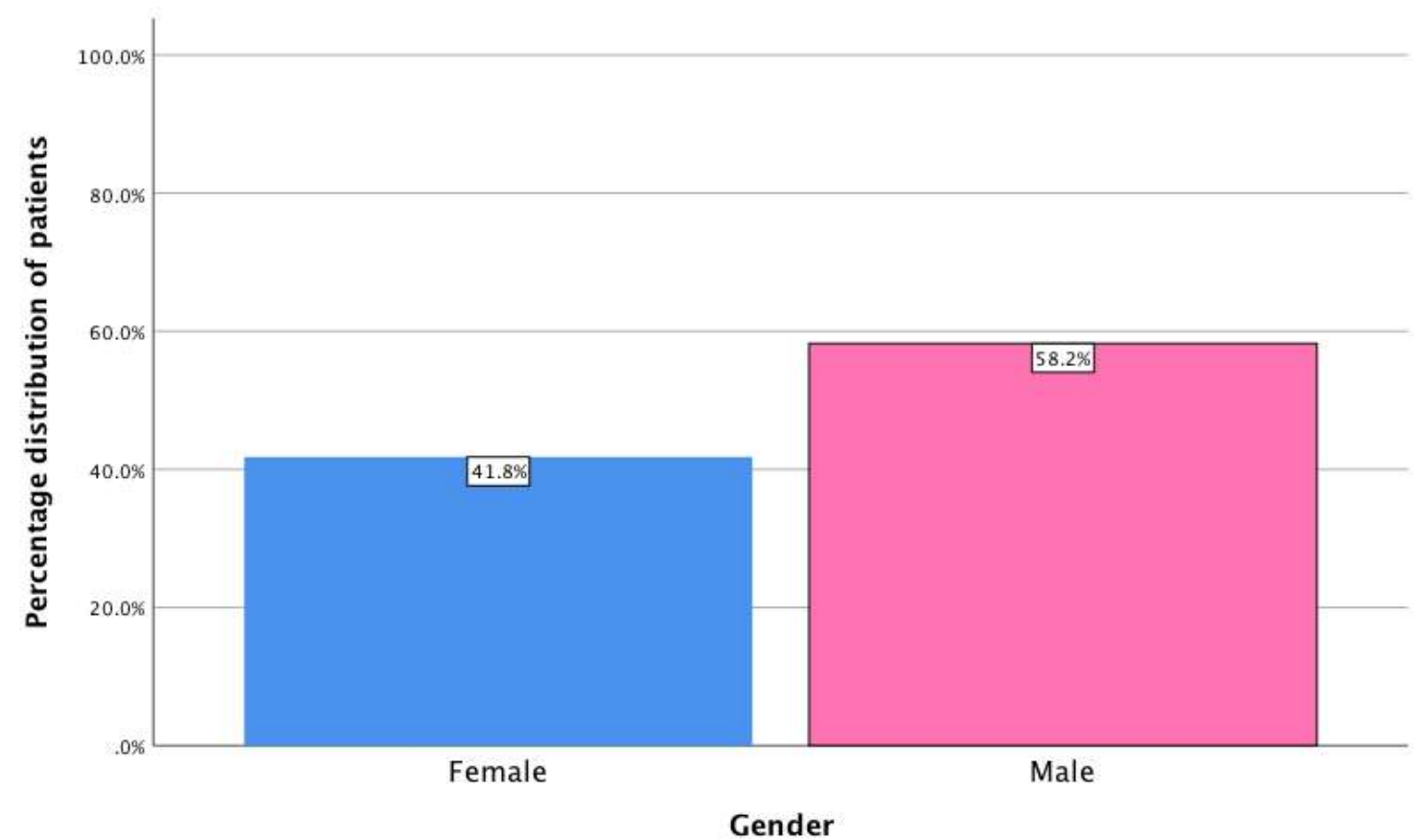

Figure 1: Bar diagram represents the percentage distribution of subjects based on gender. X-Axis represents the gender group distribution and $\mathrm{Y}$ axis represents the percentage of study subjects. $58.21 \%$ of them were males (pink) and $41.79 \%$ of them females (blue).

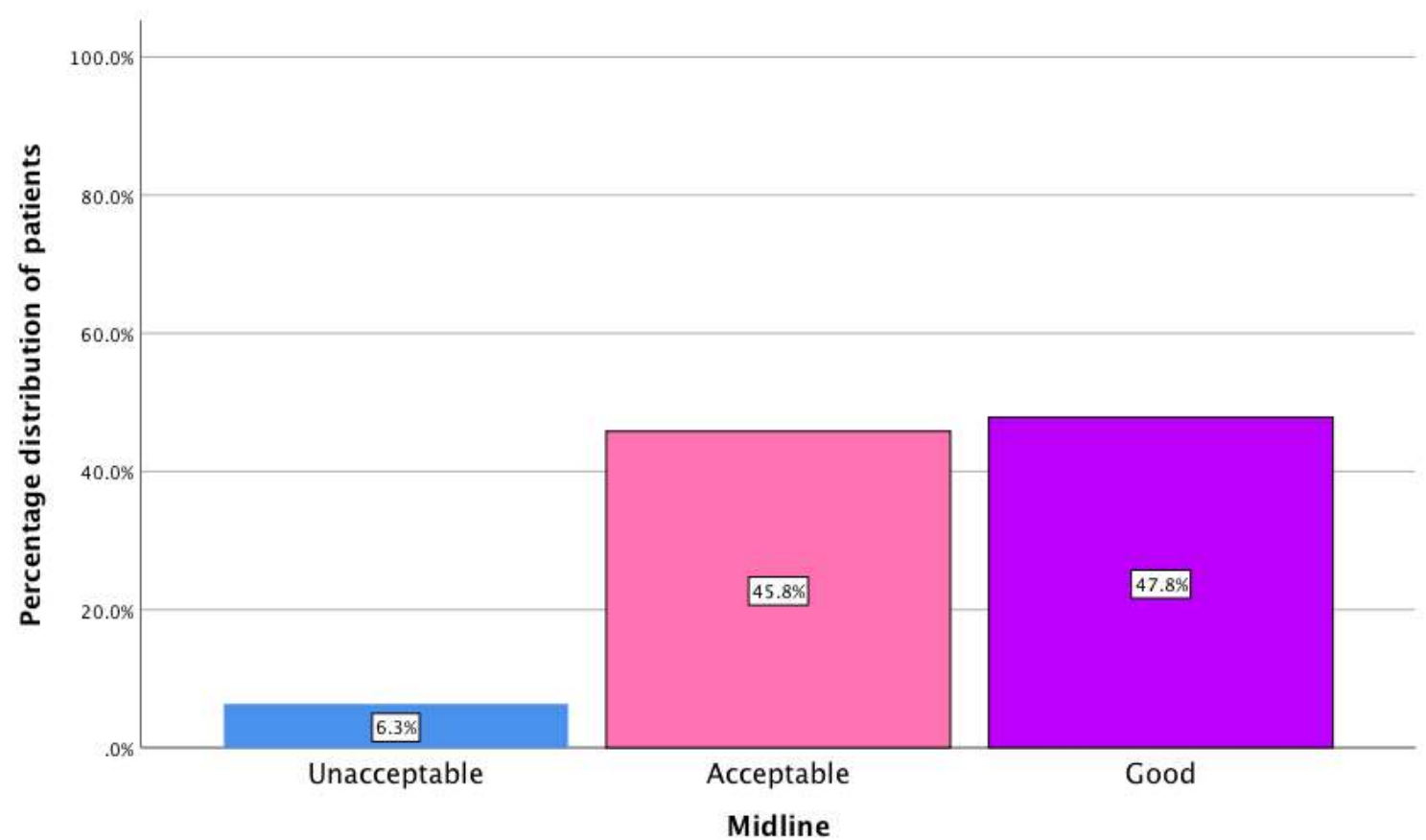

Figure 2: Bar diagram represents the percentage distribution of subjects based on midline. $X$-Axis represents the midline status of the patients and $\mathrm{Y}$ axis represents the percentage of study subjects. $6.3 \%$ of the patients had unacceptable midline status (blue), $45.8 \%$ of them had acceptable (pink) and $47.8 \%$ of patients had good midline status (purple). 


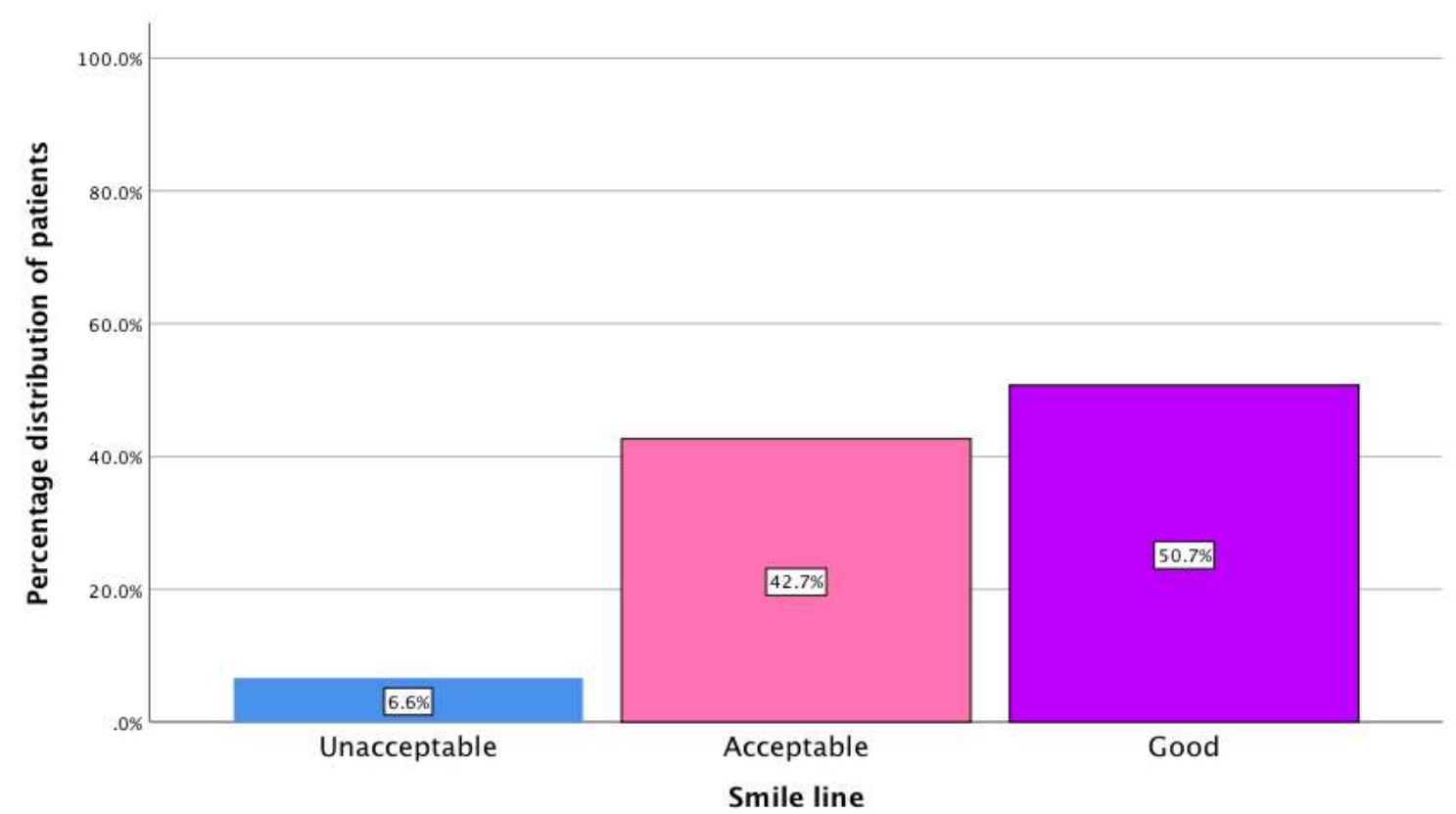

Figure 3: Bar diagram represents the percentage distribution of subjects based on smile line. $X$-Axis represents the smile line status of the patients and $\mathrm{Y}$ axis represents the percentage of study subjects. $6.6 \%$ of the patients had unacceptable smile line status (blue), $42.7 \%$ of them had acceptable smile line status (pink) and $50.7 \%$ of the patients had a good smile line status (purple).

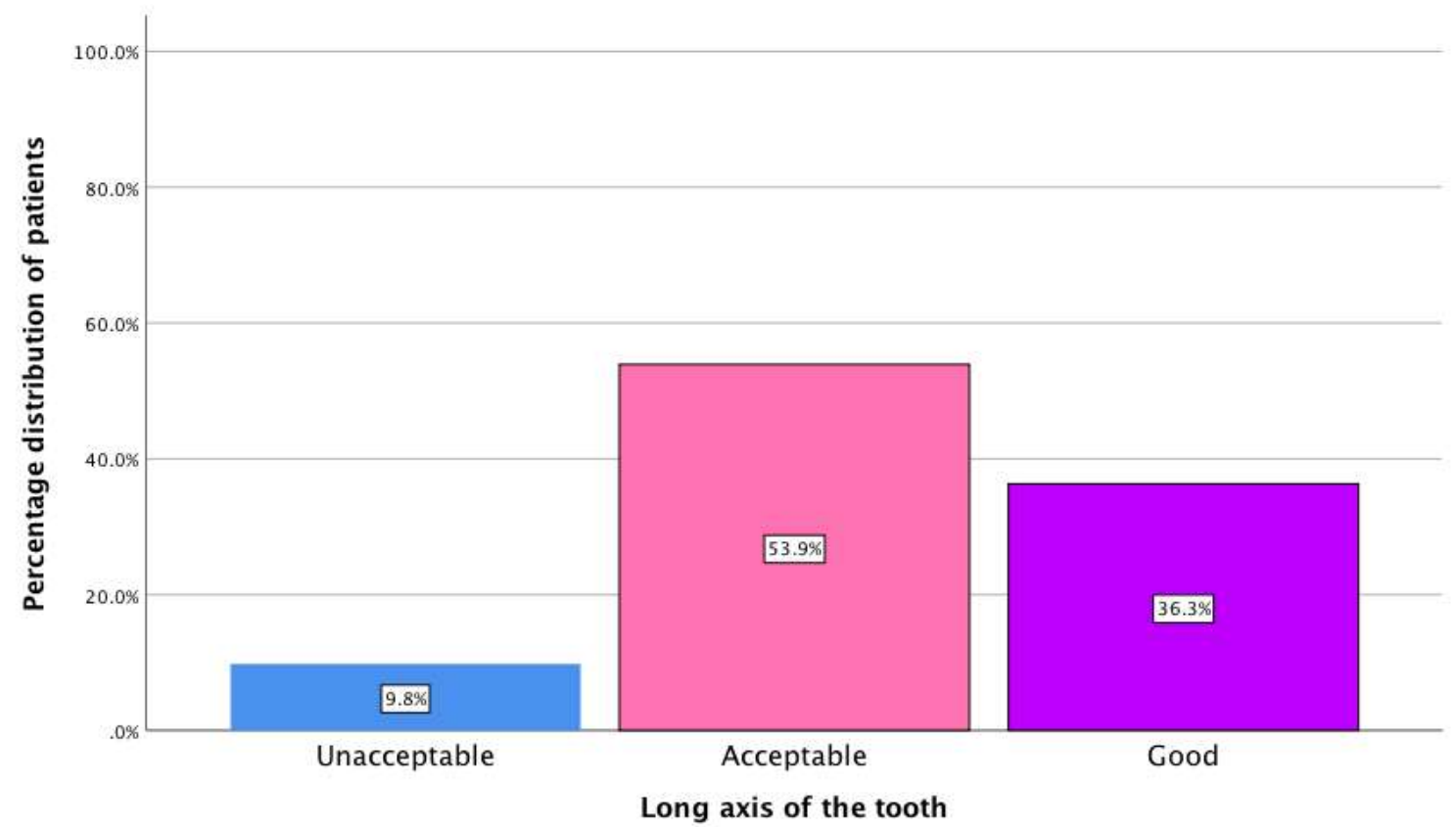

Figure 4: Bar diagram represents the percentage distribution of subjects based on the long axis of teeth . X-Axis represents the long axis of teeth distribution and $Y$ axis represents the percentage of study subjects. $9.8 \%$ of the patients had unacceptable long axis inclination status (blue), 53.9\% of them had acceptable long axis inclination status (pink) and $36.3 \%$ of the subjects had good long axis inclinations of teeth (purple). 


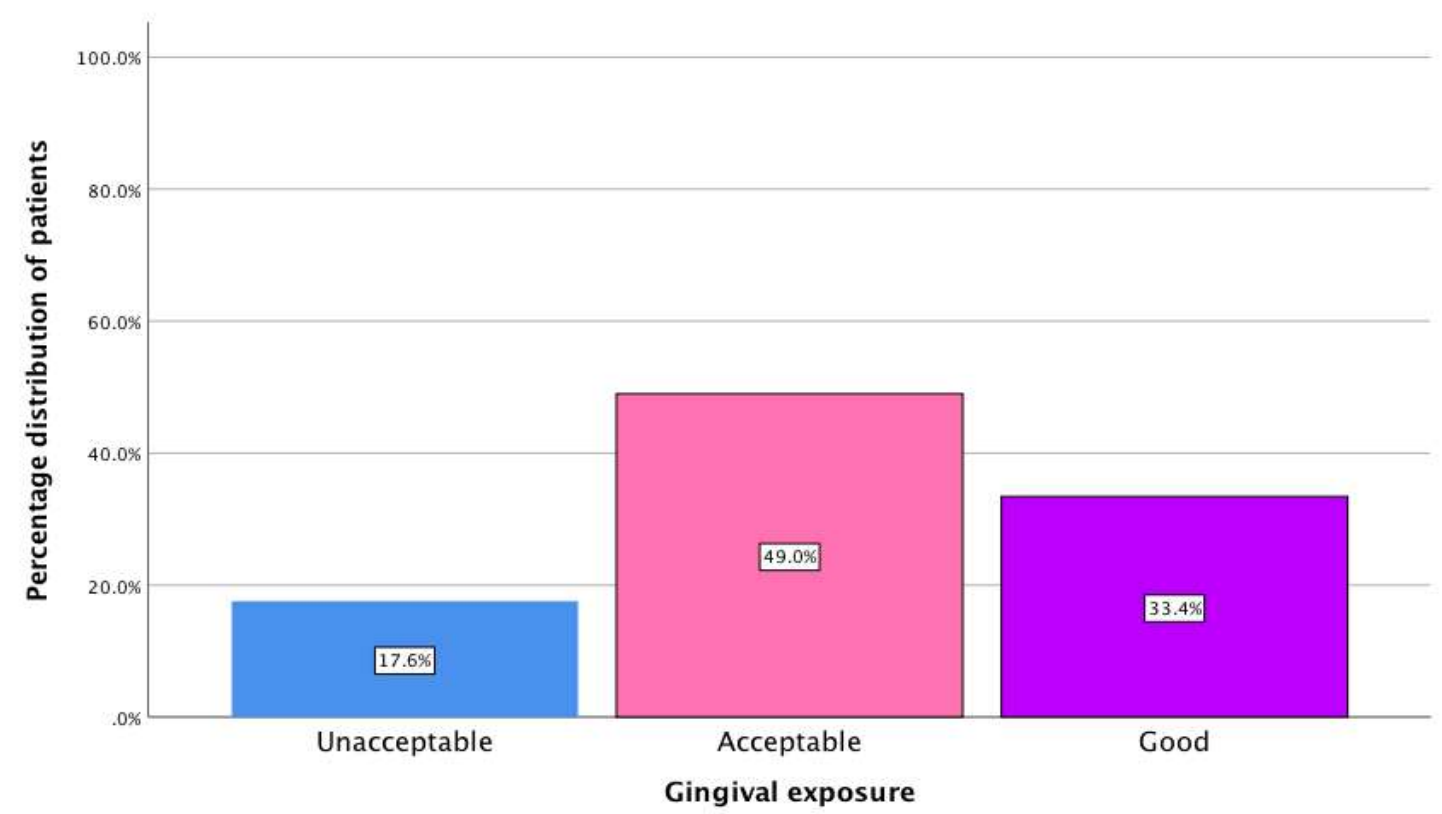

Figure 5: Bar diagram represents the percentage distribution of subjects based on gingival exposure. X-Axis represents the gingival exposure and $\mathrm{Y}$ axis represents the percentage of study subjects. $17.6 \%$ of the patients had unacceptable gingival exposure status (blue), $49 \%$ of them had acceptable gingival exposure status (pink) and $33.4 \%$ of subjects had good gingival exposure position (purple).

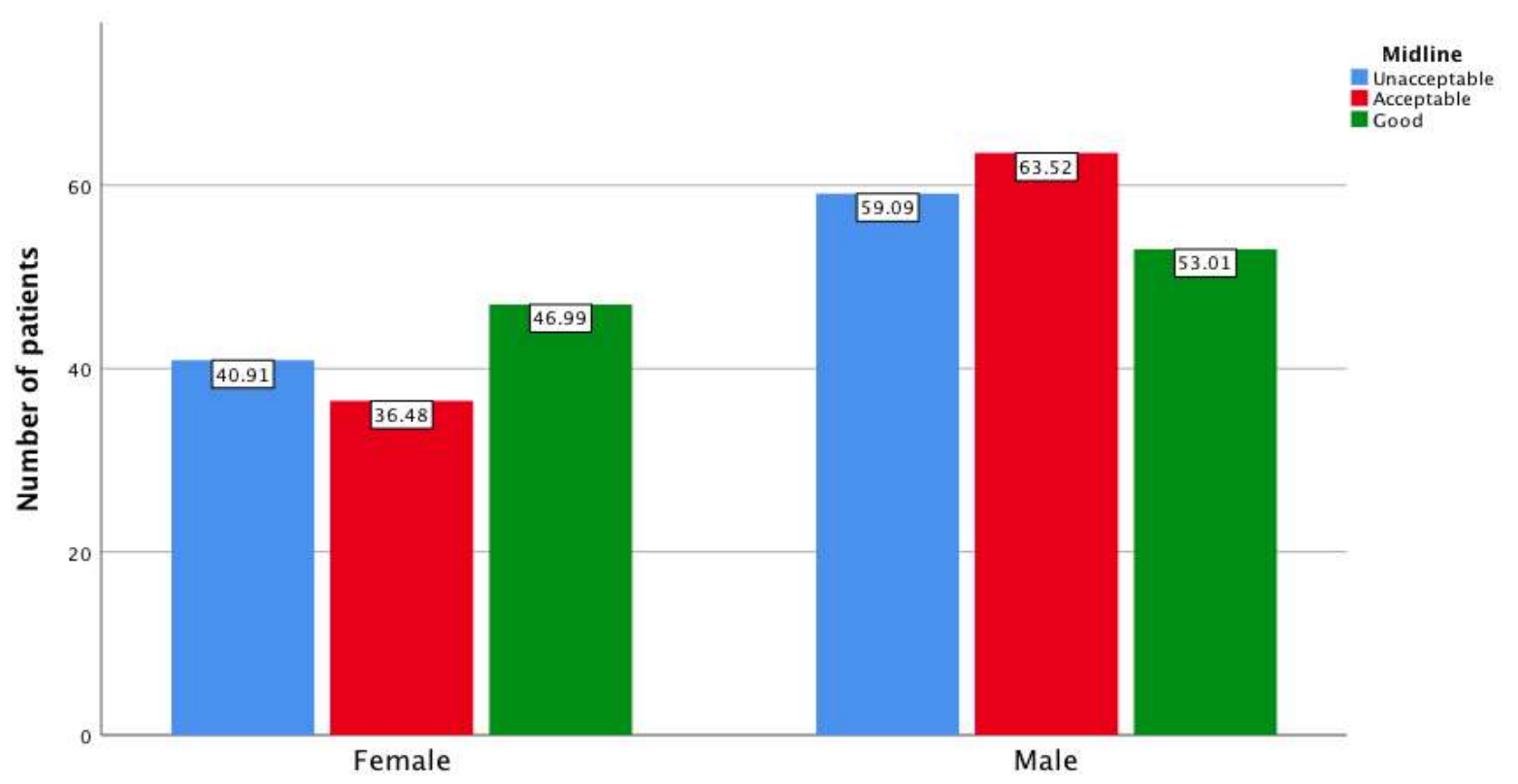

Gender

Figure 6: Bar diagram represents association between the gender and midline position of study subjects. $X$-Axis represents the gender of study subjects and $Y$ axis represents number of study subjects. Males patients had a good

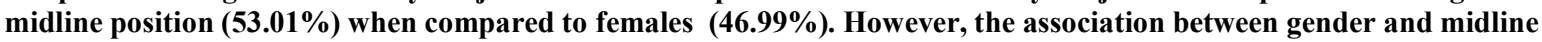
position showed no statistical significance.(Pearson Chi-square Test $\mathrm{p}=\mathbf{0 . 1 5 8 ,} \mathbf{p}>\mathbf{0 . 0 5}$ ). 


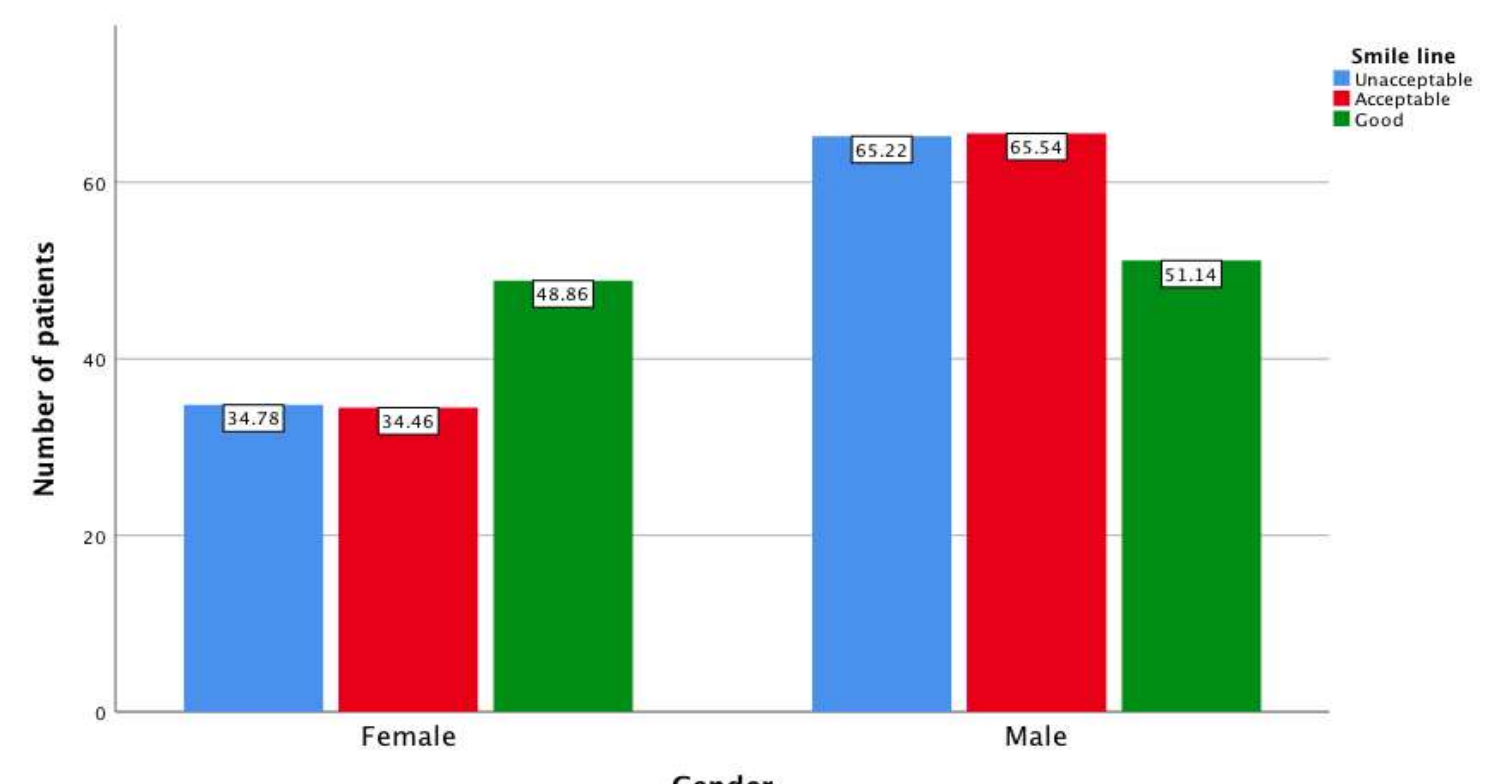

Gender

Figure

7: Bar diagram representing association between the gender and smile line of study subjects. $\mathrm{X}$-Axis represents the gender of study subjects and $Y$ axis represents number of study subjects. $65.22 \%$ of the males and $34.78 \%$ of the females had unacceptable smile line position. $34.46 \%$ of females and $65.54 \%$ of males had acceptable smile line position. Males patients had a good smile line position $(51.14 \%)$ when compared to females $(48.86 \%)$. The association between gender and smile line showed statistical significance. (Pearson Chi-square Test $\mathbf{p}=\mathbf{0 . 0 2 5}, \mathbf{p}<0.05$ ).

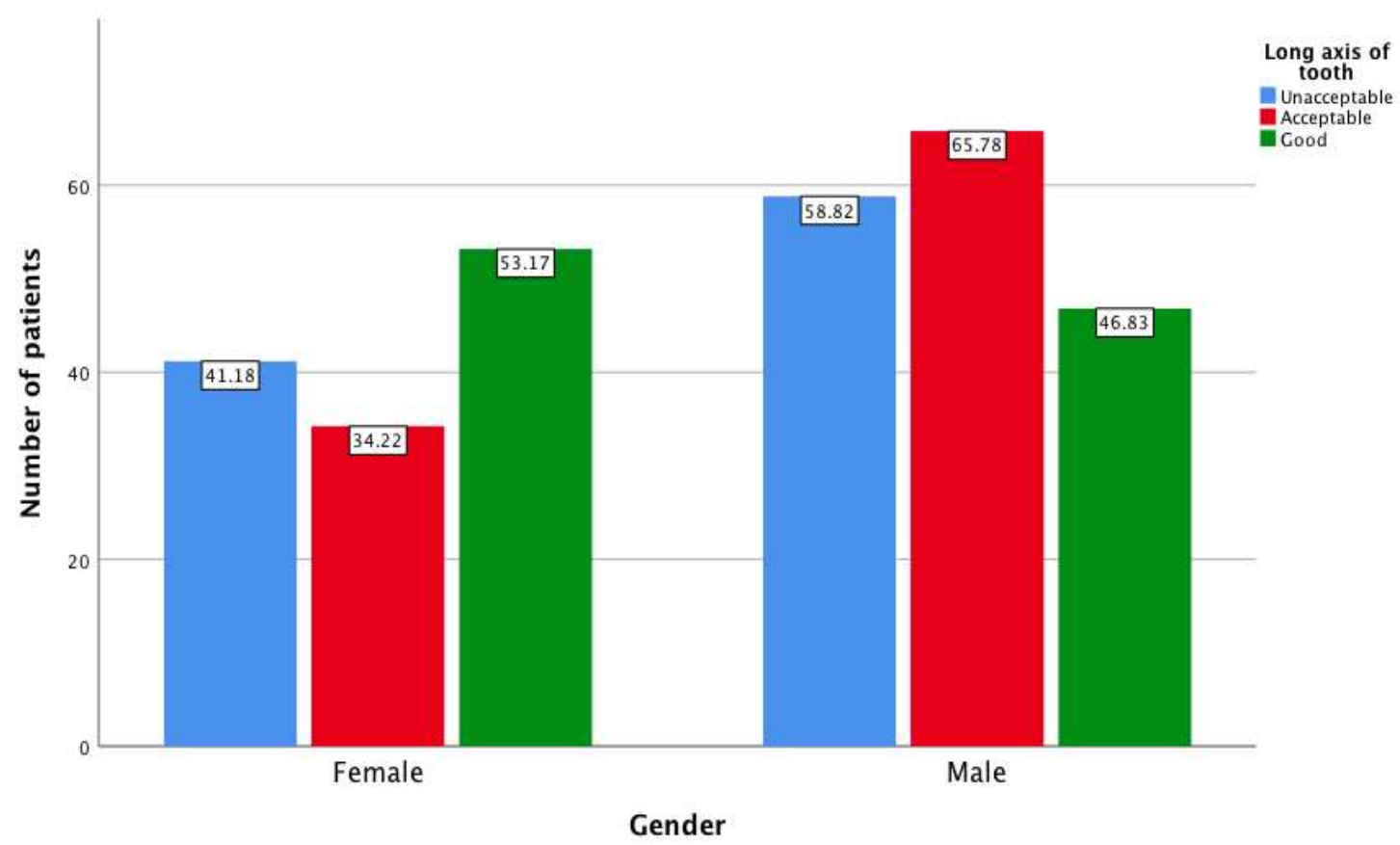

Figure 8: Bar diagram representing association between the gender and long axis inclination of teeth. $X$-Axis represents the gender of study subjects and $Y$ axis represents the number of study subjects. $41.18 \%$ of the females and $58.82 \%$ of the males had unacceptable long axis of teeth position. $34.22 \%$ of females and $65.78 \%$ of males had acceptable long axis of teeth position. Female patients $(53.17 \%)$ had a good long axis inclination of teeth than the male patients $(46.83 \%)$. The association between gender and long axis inclination of teeth showed statistical significance.(Pearson Chi-square Test $p=$ $\mathbf{0 . 0 0 4}, \mathbf{p}<0.05)$. 


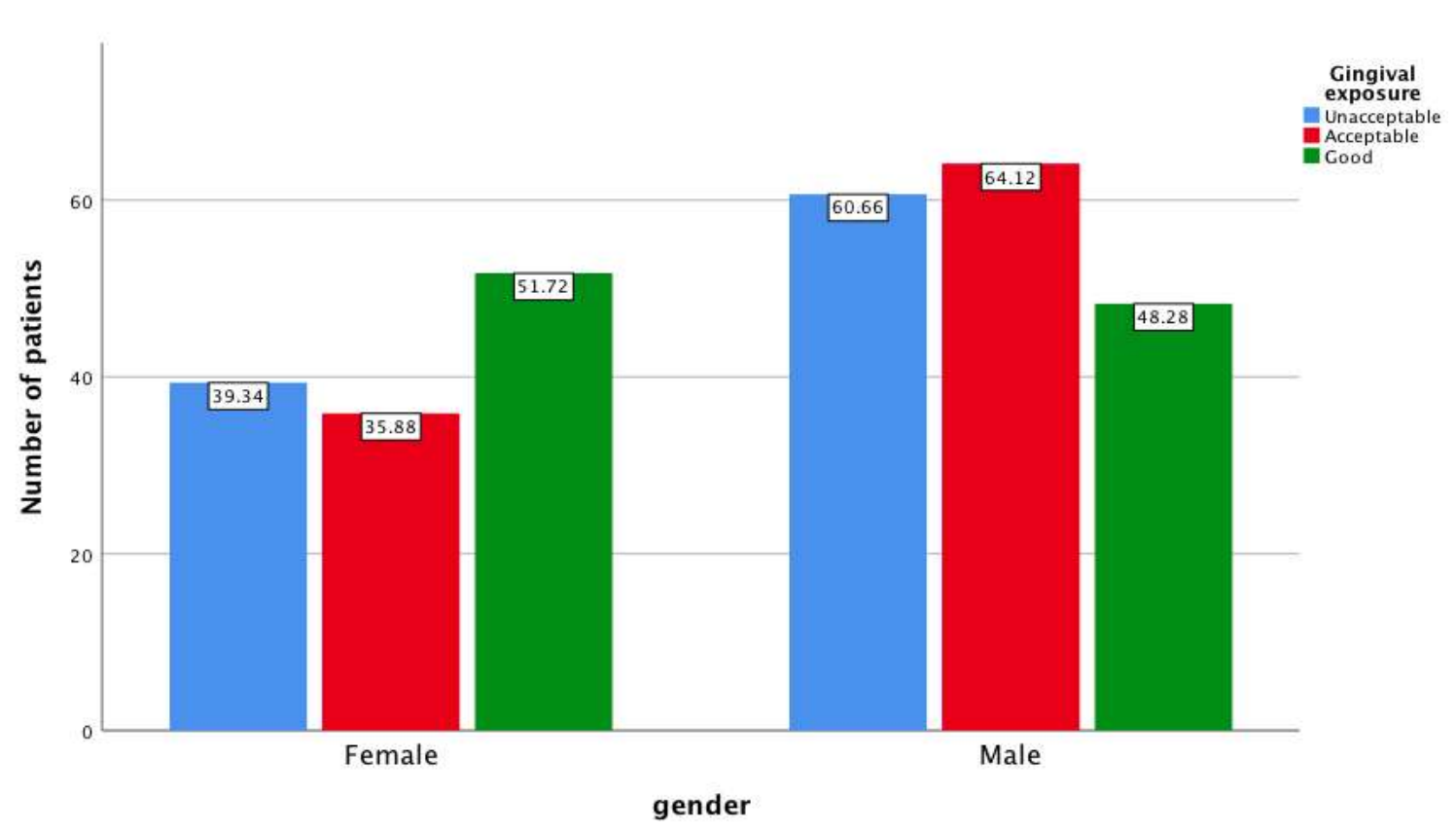

Figure 9: Bar diagram representing association between the gender and gingival exposure. $\mathrm{X}$-Axis represents the gender of the study subjects and $Y$ axis represents the number of the study subjects. $39.34 \%$ of the females and $60.66 \%$ of the males had an unacceptable gingival exposure position. $35.88 \%$ of females and $64.12 \%$ of males had acceptable gingival exposure position. Female patients $(51.72 \%)$ patients had good gingival exposure than the male patients $(\mathbf{4 8 . 2 8 \%})$. The association between gender and gingival exposure showed statistical significance.(Pearson Chi-square Test $\mathbf{p}=\mathbf{0 . 0 2 6}$, $\mathbf{p}<\mathbf{0 . 0 5 )}$.

\section{DISCUSSION}

Idealizing the artificial with the natural refers to the esthetics. The concept of esthetics was brought by Wilhelm Zech, a sculptor by profession in 1952. He incorporated some geometric designs to artificial teeth. Based on various parameters he chose teeth, like soft touch for feminine and rugged type for males. Later in 1955 the dentogenic concept was introduced which brought a revolution in artificial teeth [13]. And characterization adds a complimentary to these esthetic factors. Complete dentures must be as aesthetic as its function. According to the glossary of prosthodontics terms "Denture characterization is modification of the form and color of the denture base and teeth to produce a more life like appearance [30]." Denture esthetics includes two components teeth and the supporting denture.

The facial midline helps to evaluate the location and axis of the dental midline and also any discrepancies in the teeth position [30]. An attractive orientation of smile can be gained if the dental midline is perpendicular to the interpupillary line. Usually one or the other features of the face slant away. Eccentric midline must not be too exaggerated. Slight labial inclination to incisal or occlusal planes is acceptable. A 
curve which follows the incisal edges of central incisor, along with the incisal edges of the lateral incisor ending in the tips of the canine is known as Smile line [31]. It is considered as the primary factor for esthetics. For females, the Smile line follows the curve of lower lip but for males laterals above the centrals and canine at the level of centrals. Tooth inclinations have a variety of combinations [32]. Long axis of the tooth varies from one to another to a very minimal degree. Mesial tipping of the anteriors of axial inclinations increases as we move away from the midline. This factor should be more exaggerated if one wants more dentogenic restoration. Main part of the tooth matrix is the interdental papilla. It is a part of the denture base that is visible when the patient laughs or speaks. Four functions are being fulfilled by the interdental papilla if placed properly, hygienic interdental area,outline form of the tooth, complimentary factor and colour reflection [33]. It must extend upto the point of tooth contact and also convex which makes them self-cleansable. It must also be of various length to give a more natural look to the dentition. The tip of the papilla at its lowest point must terminate at the juncture of the labial and lingual face of the tooth [34]. It should never slope inward to terminate toward the lingual portion of the proximal surface rather turn upwards \& back to form the bottom of the groove which is known as lingual cutaway.

Previous literature do not have much records about the esthetics for complete denture wearers. No comparison has been done within the denture patients to check association and correlation between them. It is also important to consider the esthetics in complete denture wearers rather than only giving importance to dentuluous patients. More studies must be done in this context. Sometimes even many other factors can interfere in the esthetics of various studies such as geographic location, traditional habits and cultures.

\section{CONCLUSION}

Within this limitations of the study, it was seen that among the complete denture wearers women have more esthetical smiles than males with highly significant differences. This analysis can further aid in better understanding and incorporation of parameters in the fabrication of complete denture. The limitations of this study are different ethnic groups of population, moderate sample size. The future scope lies in improving the esthetics in complete denture wearers. Moreover focus on esthetics among the complete denture wearers must be given importance. 


\section{ACKNOWLEDGMENT:}

The authors of the study would like to acknowledge the support rendered by the Department of Prosthodontics, Media Records Department of Saveetha Dental College and Hospitals and the management for their constant assistance with the research.

\section{REFERENCES}

[1] Ranganathan H, Ganapathy DM, Jain AR. Cervical and Incisal Marginal Discrepancy in Ceramic Laminate Veneering Materials: A SEM Analysis. Contemp Clin Dent. 2017 Apr;8(2):272-8.

[2] Yousef M, Mokhtar HA, Abuljadayel LW, Al-Ali RM. The perception of smile attractiveness among Saudi population [Internet]. Clinical, Cosmetic and Investigational Dentistry. 2015. p. 17. Available from:

http://dx.doi.org/10.2147/ccide.s7476

4.

[3] Ganapathy D, Sathyamoorthy A, Ranganathan H, Murthykumar K. Effect of Resin Bonded Luting Agents Influencing Marginal Discrepancy in All Ceramic Complete Veneer Crowns. J Clin Diagn Res. 2016 Dec;10(12):ZC67-
70.

[4] Rodrigues C de DT, de Deus Tupinambá Rodrigues C, Magnani R, Machado MSC, Oliveira OB. The Perception of Smile Attractiveness [Internet]. Vol. 79, The Angle Orthodontist. 2009. p. 634-9. Available from: http://dx.doi.org/10.2319/030508131.1

[5] Ritter DE, Gandini LG Jr, Pinto A dos S, Ravelli DB, Locks A. Analysis of the smile photograph. World J Orthod [Internet]. 2006;7(3). Available from: https://wjo.quintessenz.de/wjo_2006 03_s0279.pdf

[6] Eli I, Bar-Tal Y, Kostovetzki I. At first glance: social meanings of dental appearance. J Public Health Dent. 2001 Summer;61(3):150-4.

[7] Newton JT, Prabhu N, Robinson PG. The impact of dental appearance on the appraisal of personal characteristics. Int $\mathrm{J}$ Prosthodont. 2003 Jul;16(4):429-34.

[8] Kenealy P, Gleeson K, Frude N, Shaw W. The importance of the individual in the "causal" relationship between attractiveness and selfesteem [Internet]. Vol. 1, Journal of 
Community \& Applied Social

Psychology. 1991. p. 45-56.

Available

from:

http://dx.doi.org/10.1002/casp.24500

10108

[9] Thompson LA, Malmberg J, Goodell NK, Boring RL. The Distribution of Attention Across a Talker's Face [Internet]. Vol. 38, Discourse Processes. 2004. p. 145-68. Available from:

http://dx.doi.org/10.1207/s15326950d p3801_6

[10] Wolfart S, Quaas AC, Freitag S, Kropp P, Gerber W-D, Kern M.

Subjective and objective perception of upper incisors. J Oral Rehabil. 2006 Jul;33(7):489-95.

[11] Lombardi RE. The principles of visual perception and their clinical application to denture esthetics. J Prosthet Dent. 1973 Apr;29(4):35882.

[12] Becker CM, Smith DE, Nicholls JI. The comparison of denture-base processing techniques. Part II. Dimensional changes due to processing. J Prosthet Dent. 1977 Apr;37(4):450-9.

[13] Jameson WS. Dynesthetic and dentogenic concept revisited. J
Esthet Restor Dent. 2002;14(3):139-48.

[14] Sarver DM, Ackerman MB. Dynamic smile visualization and quantification: Part 2. Smile analysis and treatment strategies. Am J Orthod Dentofacial Orthop. 2003 Aug;124(2):116-27.

[15] Johnson HB. Technique for packing and staining complete or partial denture bases. J Prosthet Dent. 1956 Mar 1;6(2):154-9.

[16] Tillman EJ. Molding and staining acrylic resin anterior teeth. J Prosthet Dent. 1955 Jul 1;5(4):497507.

[17] Basha FYS, Ganapathy D. Oral Hygiene Status among Pregnant Women. Research Journal of [Internet]. 2018; Available from: http://www.indianjournals.com/ijor. aspx?target=ijor:rjpt\&volume $=11 \& \mathrm{i}$ ssue $=7$ \&article $=068$

[18] Venugopalan S, Ariga P, Aggarwal P, Viswanath A. Magnetically retained silicone facial prosthesis. Niger J Clin Pract. 2014 Mar;17(2):260-4.

[19] Selvan SR, Ganapathy D. Efficacy of fifth generation cephalosporins against methicillin-resistant 
Staphylococcus aureus-A review.

Research Journal of Pharmacy and Technology. 2016;9(10):1815-8.

[20] Ashok V, Suvitha S. Awareness of all ceramic restoration in rural population. Research Journal of Pharmacy and Technology. 2016;9(10):1691-3.

[21] Jyothi S, Robin PK, Ganapathy D, Others. Periodontal health status of three different groups wearing temporary partial denture. Research Journal of Pharmacy and Technology. 2017;10(12):4339-42.

[22] Vijayalakshmi B, Ganapathy D. Medical management of cellulitis. Research Journal of Pharmacy and Technology. 2016;9(11):2067-70.

[23] Jain AR, Nallaswamy D, Ariga P, Ganapathy DM. Determination of correlation of width of maxillary anterior teeth using extraoral and intraoral factors in Indian population: A systematic review. World J Dent. 2018;9:68-75.

[24] Ashok V, Nallaswamy D, Benazir Begum S, Nesappan T. Lip Bumper Prosthesis for an Acromegaly Patient: A Clinical Report. J Indian Prosthodont $\quad$ Soc. 2014 Dec;14(Suppl 1):279-82.
[25] Kannan A, Venugopalan S. A systematic review on the effect of use of impregnated retraction cords on gingiva. Research Journal of Pharmacy and Technology. 2018;11(5):2121-6.

[26] Subasree S, Murthykumar K, Others. Effect of Aloe Vera in Oral Health-A Review. Research Journal of Pharmacy and Technology. 2016;9(5):609-12.

[27] Duraisamy R, Krishnan CS, Ramasubramanian $\quad \mathrm{H}$, Sampathkumar J, Mariappan S, Navarasampatti Sivaprakasam A. Compatibility of Nonoriginal Abutments With Implants: Evaluation of Microgap at the Implant-Abutment Interface, With Original and Nonoriginal Abutments. Implant Dent. 2019 Jun;28(3):289-95.

[28] Ganapathy DM, Kannan A, Venugopalan S. Effect of Coated Surfaces influencing Screw Loosening in Implants: A Systematic Review and Metaanalysis [Internet]. Vol. 8, World Journal of Dentistry. 2017. p. 496502. Available from: http://dx.doi.org/10.5005/jp- 
journals-10015-1493

[29] Ajay R, Suma K, Ali S, Sivakumar JK, Rakshagan V, Devaki V, et al. Effect of surface modifications on the retention of cement-retained implant crowns under fatigue loads: An In vitro study [Internet]. Vol. 9, Journal of Pharmacy And Bioallied Sciences. 2017. p. 154. Available from:

http://dx.doi.org/10.4103/jpbs.jpbs_ $146 \_17$

[30] Frush JP, Fisher RD. The dynesthetic interpretation of the dentogenic concept. J Prosthet Dent [Internet]. 1958; Available from: https://www.thejpd.org/article/00223913(58)90043-X/pdf

[31] Frush JP, Fisher RD. How dentogenic restorations interpret the sex factor. J Prosthet Dent. 1956 Mar 1;6(2):160-72.

[32] Young HA. Denture esthetics [Internet]. Vol. 6, The Journal of Prosthetic Dentistry. 1956. p. 748 55. Available from: http://dx.doi.org/10.1016/00223913(56)90071-3

[33] Frush JP, Fisher RD. How dentogenics interprets the personality factor. J Prosthet Dent. 1956 Jul 1;6(4):IN1-2.

[34] Ackerman MB, Ackerman JL. Smile analysis and design in the digital era. J Clin Orthod. 2002 Apr;36(4):221-36. 